\title{
Research funding bodies need to follow scientific evidence: preprints are here to stay
}

Dear Minister Tudge and Professor Thomas, CEO Australian Research Council,

We, the undersigned, write on behalf of a growing number of concerned academics [1] who are dismayed at the recent decision by the Australian Research Council (ARC) to rule a number of grant applications across two hallmark schemes ineligible due to references to preprints. Since preprints play a crucial role in the making and dissemination of new knowledge, we are writing to ask the ARC to reconsider their decision. In short, we call on the ARC to ensure the long-term integrity of the grant system through a range of measures:

1. Immediately change the funding rules to allow applicants to include, receive credit for, and use, in any part of their proposals of any citable, accessible, scientific or scholarly output including but not limited to journal articles, policy papers, preprints, data repositories, software, code and code libraries, and data analysis packages.

2. Reconsider the applications that have been deemed ineligible because of their references to preprints. The least the ARC can do is extend an extra year of eligibility to these researchers and issue a public apology recognising this was an unfair outcome.

3. Ensure that similar issues do not arise again by working to eliminate unclear instructions from submission rules and avoiding automated rejections of projects that would, otherwise, have merits.

Having initially grown to serve the mathematics, physics, and computer science communities, preprints are now widely accepted [2]. Overall, the practise of pre-printing has tremendous advantages $[3,4]$ and the ongoing pandemic has even further highlighted the crucial roles of preprints $[5,6]$. They not only help in breaking down structural barriers that make science and knowledge less accessible to those funding the creation of knowledge, the taxpayers, but they are also streamlining the publication process.

The decision to outright reject any proposal containing a preprint further exacerbates an incredible amount of waste of scientific resources [7,8] and, on the other hand, appears to be a draconian punishment imposed on some of the most precariously employed researchers within the academy [9]. Many of these applicants would have expended considerable research time preparing applications only to miss a few unclear instructions to the supposed inappropriateness of using preprints as a source. In ruling 
these grants ineligible it could in fact end the research careers of those who are in their last year of eligibility, on a contract that is ending, or unable to relocate for a range of reasons including the global pandemic and career responsibilities. More importantly for the ARC, however, is the fact that referencing preprints is fundamental in order to assess the quality and feasibility of a research proposal as well as the track records of applicants.

Further, the ARC has a responsibility to all taxpayers within Australia to ensure that knowledge they pay for through taxation is publicly available and accessible; including through the use of preprints. Above all else, the ARC also needs to ensure the integrity of the scheme is not tarnished by a focus on form rather than content or by excluding valid research outputs with their guidelines. By forbidding applicants to reference preprints, we would like to highlight that the ARC stands out from other international funding bodies which accept the inclusion of preprints in grant applications (e.g. European Research Council (ERC, EU), Agence Nationale de la Recherche (ANR, France), Canadian Institute for Health Research (CIHR, Canada), Bill and Melinda Gates Foundation (International), National Institutes of Health (NIH, USA); a more complete list available here [10]). By going against current best practices, Open Science and transparency principles, we fear that the ARC is hindering the quality and integrity of its funding schemes and its reputation as a funding body. For all these reasons, we argue that the measures listed above should be considered by the ARC. Scientific evidence is clear: preprints are here to stay.

Anthony W. Lanati, ${ }^{1,2}$ Olivier Pourret, ${ }^{3}$ Christopher Jackson, ${ }^{4}$ Lonni Besançon ${ }^{5}$

${ }^{1}$ Department of Earth and Environmental Sciences, Macquarie University, North Ryde, NSW 2109, Australia;

${ }^{2}$ Institut für Mineralogie, Westfälische Willhelms-Universität Münster, Corrensstraße 24, D-48149

Münster, Germany

anthony.lanati@ma.edu.au ORCID:0000-0002-3317-5697

${ }^{3}$ UniLaSalle, AGHYLE, Beauvais, France.

olivier.pourret@unilasalle.fr ORCID: 0000-0001-6181-6079

${ }^{4}$ Department of Earth and Environmental Sciences, The University of Manchester, UK. christopher.jackson@manchester.ac.uk ORCID: 0000-0002-8592-9032

${ }^{5}$ Faculty of Information and Technology, Monash University, Australia. lonni.besancon@gmail.com ORCID: 0000-0002-7207-1276 
References:

[1] A complete list of all co-signatories is available on https://osf.io/rudmv/

[2] Pourret, O., Irawan, D.E., Tennant, J.P., 2020. On the Potential of Preprints in Geochemistry: The Good, the Bad, and the Ugly. Sustainability, 12(8). https://doi.org/10.3390/su12083360.

[3] Fry, N. K., Marshall, H., \& Mellins-Cohen, T. (2019). In praise of preprints. Access Microbiology, 1(2). DOI: https://doi.org/10.1099/acmi.0.000013

[4] Berg, J. M., Bhalla, N., Bourne, P. E., Chalfie, M., Drubin, D. G., Fraser, J. S., ... \& Wolberger, C. (2016). Preprints for the life sciences. Science, 352(6288), 899-901. DOI: 10.1126/science.aaf9133

[5] Fraser N, Brierley L, Dey G, Polka JK, Pálfy M, et al. (2021) The evolving role of preprints in the dissemination of COVID-19 research and their impact on the science communication landscape. PLOS Biology 19(4): e3000959. https://doi.org/10.1371/journal.pbio.3000959

[6] Besançon, L., Peiffer-Smadja, N., Segalas, C. et al. Open science saves lives: lessons from the COVID-19 pandemic. BMC Med Res Methodol 21, 117 (2021). https://doi.org/10.1186/s12874-021-01304-y

[7] Herbert DL, Barnett AG, Clarke P, et al. On the time spent preparing grant proposals: an observational study of Australian researchers. BMJ Open (2013); 3:e002800. doi: https://doi.org/10.1136/bmjopen-2013-002800

[8] Bailes, M., Bradby, J., et al. (2021). Letter to Ministers Sukkar, M. and Tudge, A. "No-or-low cost opportunities for a better, fairer research grant system", https://treasury.gov.au/sites/default/files/2021-05/171663 bradby professor jodie.pdf

[9] Sarabipour S, Debat HJ, Emmott E, Burgess SJ, Schwessinger B, et al. (2019) On the value of preprints: An early career researcher perspective. PLOS Biology 17(2): e3000151. https://doi.org/10.1371/journal.pbio.3000151

[10] https://asapbio.org/funder-policies 